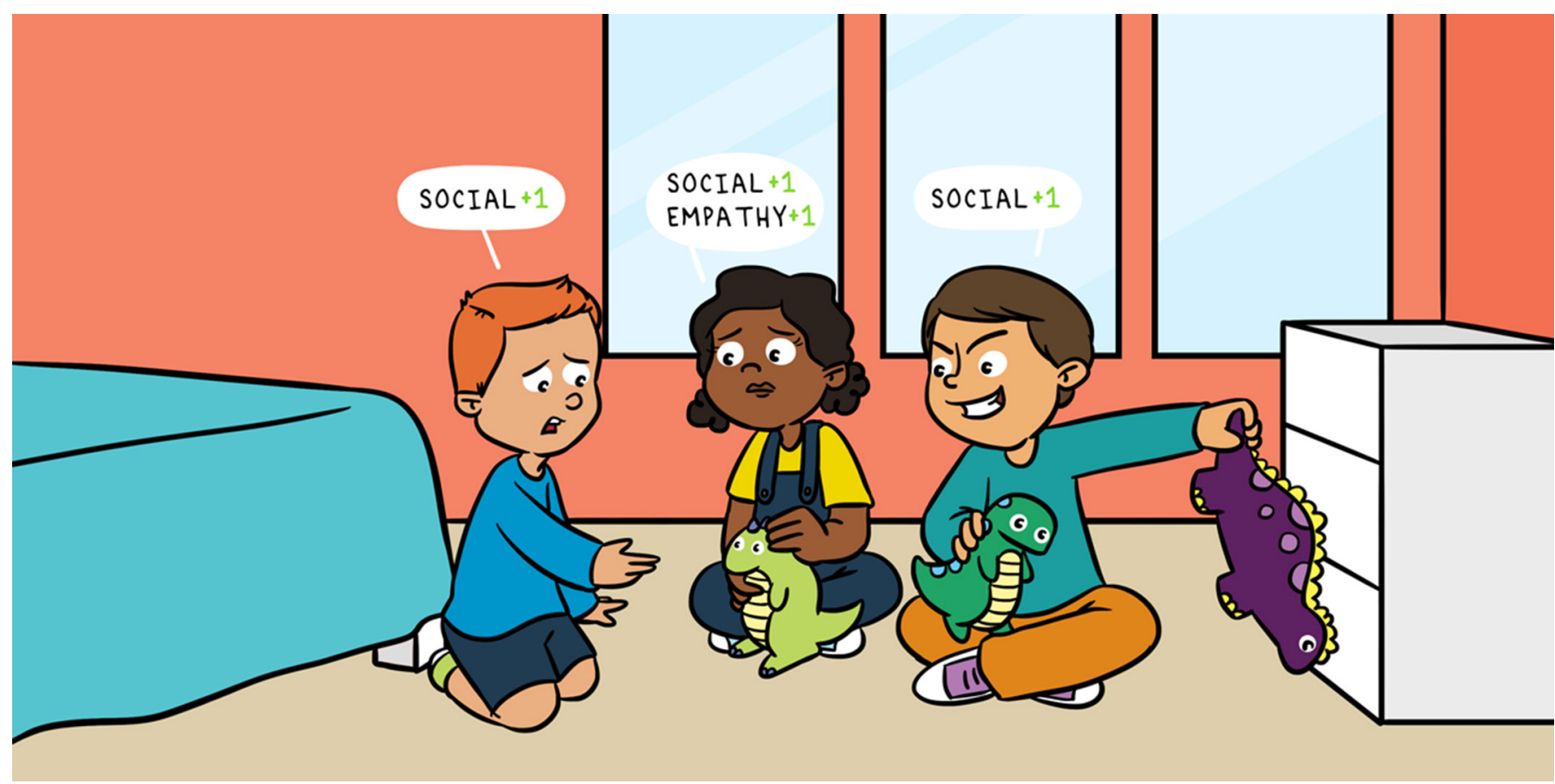

\title{
WHAT IS HAPPENING IN CHILDREN'S BRAINS WHEN THEY ARE PLAYING PRETEND?
}

\section{Emma Aanestad ${ }^{1}$, Marvellous John ${ }^{1}$, Eliza Melkonyan ${ }^{1}$, Salim Hashmi ${ }^{2}$, Sarah Gerson ${ }^{3 *}$ and Ross E. Vanderwert ${ }^{3,4}$}

${ }^{1}$ Department of Psychology, St. Olaf College, Northfield, MN, United States

${ }^{2}$ Department of Psychology, Institute of Psychiatry, Psychology and Neuroscience, King's College London, London, United Kingdom

${ }^{3}$ School of Psychology, Cardiff University Centre for Human Developmental Science (CUCHDS), Cardiff, United Kingdom ${ }^{4}$ School of Psychology, Cardiff University Brain Research Imaging Centre (CUBRIC), Cardiff, United Kingdom

\section{YOUNG REVIEWERS:}
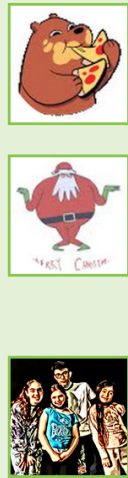

SANJITH

AGE: 10

SUSHAEN

AGES: 12

THE

SCHECHT-

MAN

FAMILY

AGES: 9-14
Our brains are active while we learn, work, and even play! We wanted to find out what parts of the brain kids use when they play with dolls. Because pretend play with dolls might involve imagining how other people act and feel, we thought that the areas of the brain used for thinking about other people might be particularly important during doll play. If this is true, do kids use these parts of the brain in all types of pretend play or is there something special about playing with dolls? Are the brain regions that are important for thinking about other people used in the same way when playing with an iPad vs. with dolls? Do kids use the social parts of their brains when playing pretend on their own, or only with a friend? Let us talk about what we found! 
Figure 1

The posterior superior temporal sulcus (pSTS) is the area of the brain that is associated with developing social understanding and empathy.

\section{PRETEND PLAY}

Play in which we create a playful version of our own reality, for fun.

\section{EMPATHY}

The ability to feel or understand the experiences of another person.

\section{POSTERIOR}

SUPERIOR

TEMPORAL SULCUS

(PSTS)

A part of the brain associated with developing social understanding and empathy.

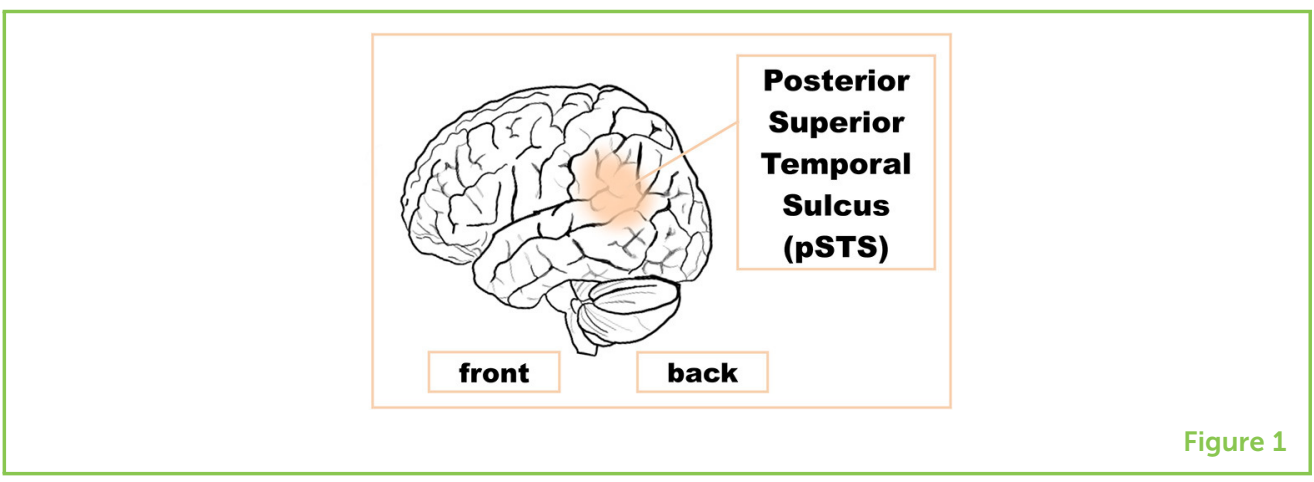

\section{WHEN YOU THINK OF PLAY, WHAT DO YOU THINK OF?}

Play can take many different forms: fantasy or pretend play, games with rules, word play, construction play, or all of them combined into one. Play is simply something children find fun. One of the most common forms of play is pretend play, in which we create a playful, imaginary version of our world for fun. Pretend play is really common when children play with toys, particularly dolls. Doll play is particularly exciting because you can still have fun whether you play alone or with someone else.

Some research has shown that pretend play with others is useful for improving our social skills. In other words, while the play is not "real" to us nor our friend, it does allow us to practice real social skills, like recognizing when our friend is pretending, and practicing how to respond to the various emotional reactions of another person. Some other experiments have found that pretend play allows children to explore their own feelings and emotions, and to learn about empathy [1]. Empathy is the ability to "put yourself in someone else's shoes," to understand how they might be feeling in a certain situation. For example, you might understand that your friend probably feels sad when someone takes his or her favorite toy away. Empathy is very important when it comes to understanding others' feelings and desires, and it is the first step toward helping other people feel better. To learn more about empathy, you can read this Frontiers for Young Minds article.

Past research has found that there is a particular area of the brain that is especially important in helping us to know when to show empathy. That brain area is the posterior superior temporal sulcus (pSTS) (Figure 1) and, in our study, we collected data from this brain region to see what happened during pretend play $[2,3]$. Our study was unique because we studied children who were either playing with a play-partner (joint play) or alone (solo play), to see if playing with a partner affects a child's ability to gain and use various social skills. To investigate these questions, we decided to measure children's brain activity during live, natural play. Think of this as having a live recording of what is happening in your brain while you are playing. 


\section{Figure 2}

To study the brain using fNIRS, a stretchy cap with light sources and detectors is placed on the child's head. The cap shines near-infrared light into the brain to see which parts are active while the child is playing. fNIRS recording is a safe, pain-free process The yellow arcs in the picture show where the light travels through the brain.

\section{FUNCTIONAL}

NEAR-INFRARED SPECTROSCOPY (FNIRS)

A technique that uses near-infrared light to measure blood flow in the brain. Regions that are active need more blood.

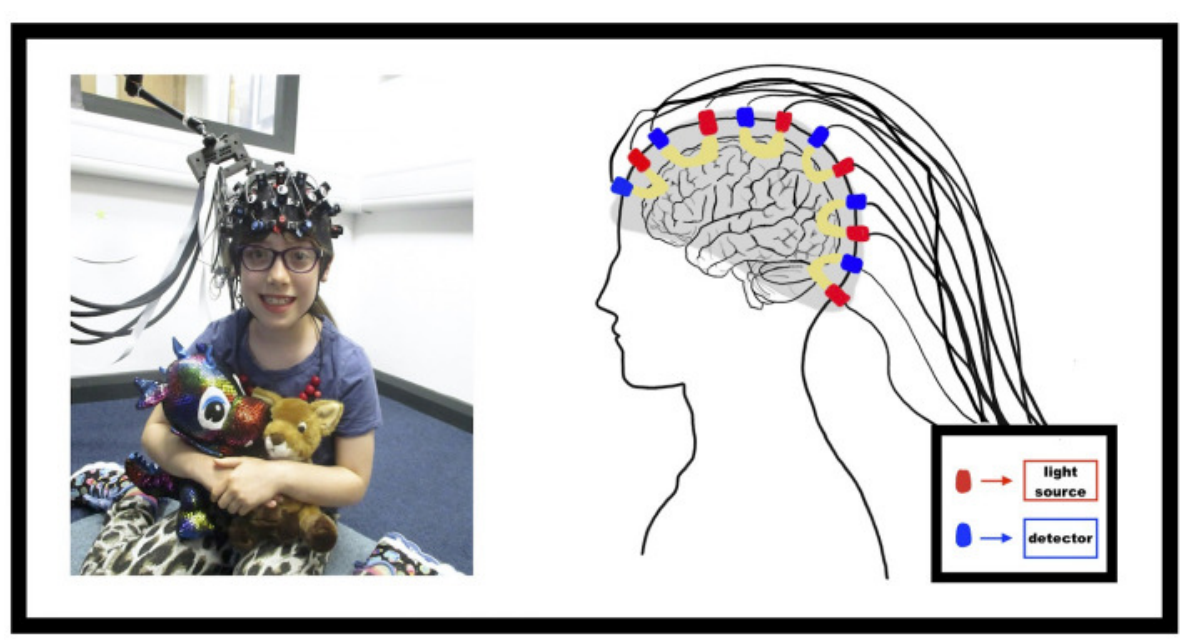

Figure 2

\section{HOW DID WE STUDY THE BRAIN DURING PRETEND PLAY?}

To see which areas of the brain were active during pretend play, we used a technique called functional near-infrared spectroscopy (fNIRS). Researchers put a special stretchy cap on the children they are studying. By shining a special kind of light, called near-infrared light, through the skin, bone, and brain, this cap can detect which parts of the brain are being used (Figure 2). Although this may sound scary, near-infrared light is much like the other types of light that we experience in our daily lives and is perfectly safe and painless. As this light passes through the head, some of it is absorbed by the blood flowing through the brain. When our brains are active, they require oxygen from the bloodstream. So, the harder a particular area of the brain is working, the more oxygenated blood will be sent to that area and the more light will be absorbed there. Because the fNIRS cap measures how much light comes back out of the brain, the areas with less light shining through them are the most active. To learn more about fNIRS, see this article. fNIRS was a good technique to choose for our study, because it does not require the person being studied to hold still for brain activity to be measured. This was helpful, because it allowed us to see what was happening in the brain as kids moved around to talk and play with toys, the way they normally would [4].

We hoped to answer three main questions with our research. First, we wanted to know whether the PSTS was active during pretend play. If so, would the PSTS be more active when the child was playing pretend alone vs. with someone else? Last, we wondered whether the type of toy being used during pretend play influences which brain areas are activated. 
Figure 3

(A) Our experiment contained 4-min segments of play, either with dolls or a tablet. Some segments were solo, and some were joint. Between each segment, children watched a short video to reset. (B) Our results showed that there was more pSTS activity during solo doll play than solo tablet play. The $y$-axis shows the amount of oxygen in the blood flowing through the pSTS during the experiment.

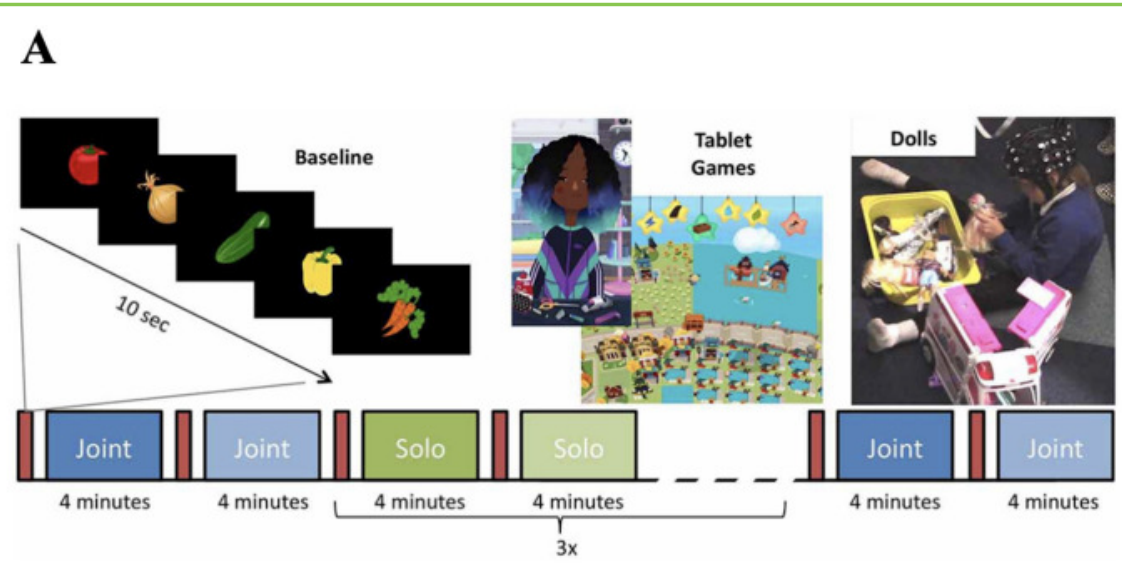

B

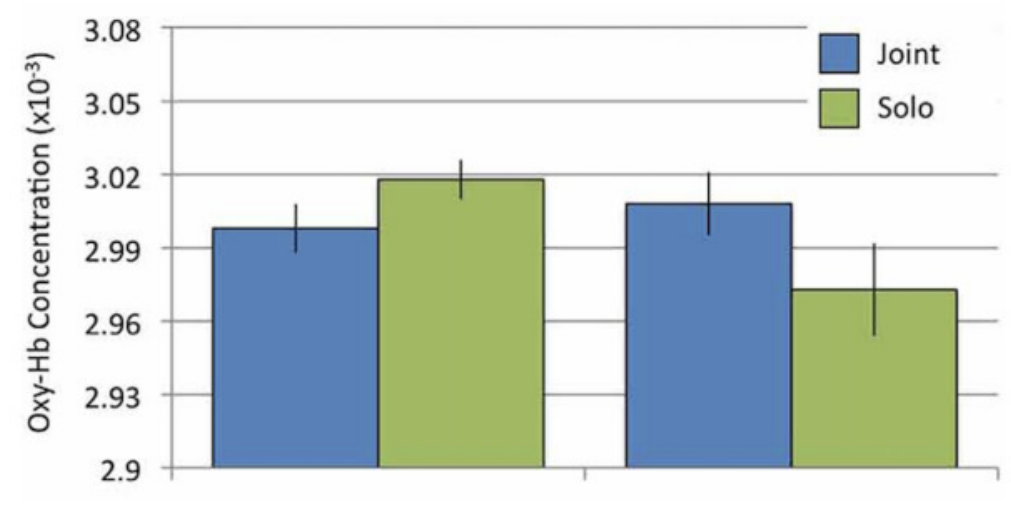

Doll

\section{HOW DID WE ANSWER OUR QUESTIONS?}

We invited 42 children between 4 and 8 years old to participate in our study. We were able to collect full fNIRS data from 33 of the 42 participants. Each participant was asked to play two types of games: tablet games and doll games. We had two different tablet games (a city-building game and a hair-dressing game), and four different sets of dolls: a family set, a careers set, a house set, and an animals set.

Each segment involved 4 min of rule-free, creative, play. Between segments, we showed participants a 10 -s video containing pictures of vegetables, as a reset before the next play segment (Figure 3A). During the joint doll and joint tablet segments, the children were given dolls or a tablet game to play with, and the experimenter was allowed to play with them. During the solo doll and solo tablet segments, the experimenter just observed while the children played on their own. 


\section{WHAT DID WE FIND?}

As we mentioned earlier, the pSTS is associated with developing social understanding and empathy. In this case, social understanding refers to the way we can build relationships with other people by noticing and responding to their social cues, like expressions, body language, and tone of voice. In our study, we wanted to see if the pSTS was active when kids were playing pretend with someone else and/or when they were playing pretend alone. We saw that the pSTS was activated during all types of pretend play. We also wanted to see if play with dolls activated the pSTS region more than play with a tablet. On average, pretend play with the dolls was associated with greater activation of the pSTS than pretend play with the tablet. Our results also showed that when children are playing with someone else, the pSTS is activated to a very similar degree, regardless of whether they are playing with dolls or with a tablet. However, during solo play, there was greater activation of the pSTS when children were playing with dolls as opposed to a tablet (Figure 3B). We found these results for both boys and girls, and across all the ages we assessed.

\section{WHY IS THIS IMPORTANT?}

fNIRS brain imaging confirmed our hypothesis that an area of the brain known to play a role in social understanding and empathy, the pSTS, was active during pretend play. Interestingly, we saw that the pSTS was not only active when kids were playing pretend with someone else, but also when they were playing pretend on their own! This is an intriguing new finding, because it suggests that playing pretend with friends may not be the only way for children to further develop their capacity for empathy and social understanding. However, we also found that the type of toy children play with on their own affects how much the pSTS is activated. The pSTS was more activated during solo play with dolls than during solo play with a tablet. Our finding that solo doll play, rather than solo tablet play, activates the pSTS more suggests that dolls are better suited to help children develop these social skills than are imaginative, open-ended tablet games.

These results are important because they suggest that playing with dolls by ourselves is one way we can practice important social skills like empathy. However, there is still a lot of research that needs to be done into why certain types of toys activate the pSTS more than others. Maybe you can be the future researcher who helps us figure it out!

\section{ACKNOWLEDGMENTS}

Written informed consent was obtained from the individual(s), and/or minor(s)' legal guardian/next of kin, for the publication of any potentially identifiable images or data included in this article. 


\section{ORIGINAL SOURCE ARTICLE}

Hashmi, S., Vanderwert, R. E., Price, H. A., and Gerson, S. A. 2020. Exploring the benefits of doll play through neuroscience. Front Hum Neurosci. 14:560176. doi: 10.3389/fnhum.2020.560176

\section{REFERENCES}

1. Levy, J., and Feldman, R. 2017. Can teenagers feel the pain of others? Peeking into the teenage brain to find empathy. Front Young Minds. 5:59. doi: 10.3389/frym.2017.00059

2. Hashmi, S., Vanderwert, R. E., Price, H. A., and Gerson, S. A. 2020. Exploring the benefits of doll play through neuroscience. Front Hum Neurosci. 14:560176. doi: $10.3389 /$ fnhum.2020.560176

3. Lahnakoski, J. M., Glerean, E., Salmi, J., Jääskeläinen, I. P., Sams, M., Hari, R., et al. 2012. Naturalistic fMRI mapping reveals superior temporal sulcus as the hub for the distributed brain network for social perception. Front Hum Neurosci. 6:233. doi: 10.3389/fnhum.2012.00233

4. Soltanlou, M., and Artemenko, C. 2020. Using light to understand how the brain works in the classroom. Front Young Minds. 8:88. doi: 10.3389/frym.2020.00088

SUBMITTED: 19 December 2020; ACCEPTED: 29 October 2021;

PUBLISHED ONLINE: 06 December 2021.

EDITED BY: Shekher Mohan, Liberty University, United States

CITATION: Aanestad E, John M, Melkonyan E, Hashmi S, Gerson S and Vanderwert RE (2021) What Is Happening in Children's Brains When They Are Playing Pretend? Front. Young Minds 9:644083. doi: 10.3389/frym.2021.644083

CONFLICT OF INTEREST: The authors declare that the research was conducted in the absence of any commercial or financial relationships that could be construed as a potential conflict of interest.

Funding for this project was provided by Mattel $\operatorname{lnc}{ }^{\circledR}$; through partnership with Oxy Insight Ltd. Mattel and Oxy Insight funded the equipment and some personnel for this project and were involved in initial discussions regarding the study design. Neither Mattel or Oxy Insight had final say in the study design nor played a direct role in the collection or analysis of the data; interpretation of the results; or writing of the manuscript.

COPYRIGHT @ 2021 Aanestad, John, Melkonyan, Hashmi, Gerson and Vanderwert. This is an open-access article distributed under the terms of the Creative Commons Attribution License (CC BY). The use, distribution or reproduction in other forums is permitted, provided the original author(s) and the copyright owner(s) are credited and that the original publication in this journal is cited, in accordance with accepted academic practice. No use, distribution or reproduction is permitted which does not comply with these terms. 

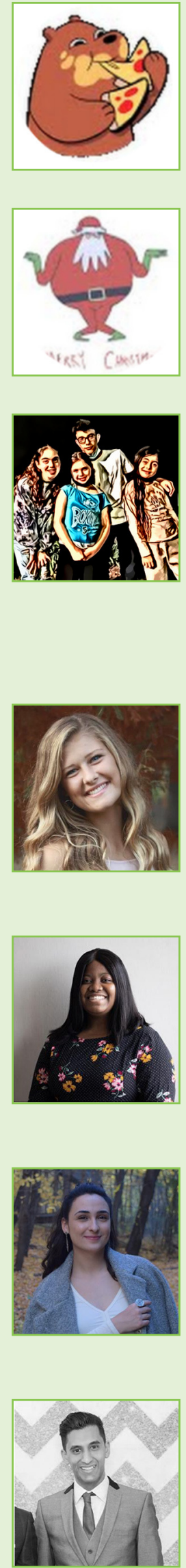

\section{YOUNG REVIEWERS}

\section{SANJITH, AGE: 10}

I like building things and I like to read a lot. I like scientific experiments and I am always curious about how to piece things together.

\section{SUSHAEN, AGE: 12}

I like to read a lot and I am curious about how the brain works. I love playing cricket and basketball and watch any sports.

\section{THE SCHECHTMAN FAMILY, AGES: 9-14}

We are Ori, Mika, Roni, and Alona-a group of cousins living in Tel-aviv and Gedera, Israel. We enjoy meeting for Friday night dinner at our grandma's house. We each have different hobbies and fields of interest, but what we do have in common is our love for both hiking and science.

\section{AUTHORS}

\section{EMMA AANESTAD}

I am an undergraduate student studying psychology, neuroscience, and statistics/ data science. I am especially interested in an area of psychology known as neuropsychology, which investigates how the brain controls the way that people think and behave. In my spare time, you can find me curled up with a book, running/hiking outdoors, or journaling!

\section{MARVELLOUS JOHN}

I am a senior psychology major at St. Olaf College (MN, USA). I am interested in child psychology research and how it benefits medical care. When I am not studying for a test, I enjoy swimming, catching up on TV shows, and cooking.

\section{ELIZA MELKONYAN}

I am a senior psychology major from Armenia at St. Olaf College. I am interested in clinical psychology, more specifically in exploring child abnormal psychology and how it changes across cultures. A big passion of mine is the arts, especially dance and music. I am interested in exploring these fields in the diagnosis and treatment of psychopathology.

\section{SALIM HASHMI}

I am a lecturer in psychology and my research interests are in children's imagination and play. I am particularly interested in how imagination and play may be changing as children are spending lots of their time on electronic devices. When not doing research, most of my time is spent teaching undergraduate students, which I love 


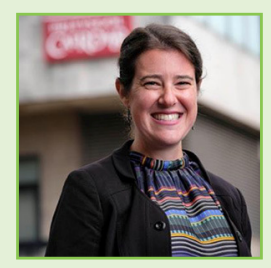

doing! In my spare time, I enjoy exploring London, reading, playing video games, and staring at photos of my cat (her name is Dusty).

\section{SARAH GERSON}

I am a senior lecturer in psychology and I study how children learn about the world. Children are constantly watching and interacting with other people, and I want to find out how they make sense of these other people and what they are doing. When not doing research, I enjoy running, reading, and traveling. *Gersonsacardiff.ac.uk

\section{ROSS E. VANDERWERT}

I am a developmental neuroscientist interested in how our early childhood experiences with parents, friends, and our environments change the way our brains function. I ask the question: how can we improve childhood experiences to ensure healthy outcomes? When I am not doing research, I enjoy playing with my daughter and dog, going for long runs, and visiting historic architecture. 